\title{
Erratum to: The Cerro Bitiche Andesitic Field: petrological diversity and implications for magmatic evolution of mafic volcanic centers from the northern Puna
}

\author{
Guadalupe Maro $^{1} \cdot$ Pablo J. Caffe ${ }^{1}$
}

Published online: 25 August 2016

(C) Springer-Verlag Berlin Heidelberg 2016

Erratum to: Bull Volcanol (2016) 78: 51

DOI 10.1007/s00445-016-1039-y

All coordinates of the samples given on Table 1 are unfortunately incorrect. Latitude and longitude are expressed as decimal degrees. Therefore, there must be only one period and its correct position is after the second number.

The online version of the original article can be found at http://dx.doi. org/10.1007/s00445-016-1039-y.

Guadalupe Maro

maroguadalupe@gmail.com

Instituto de Ecorregiones Andinas (INECOA), Universidad Nacional de Jujuy - CONICET, Instituto de Geología y Minería, Av. Bolivia 1661, San Salvador de Jujuy CP 4600, Jujuy, Argentina 


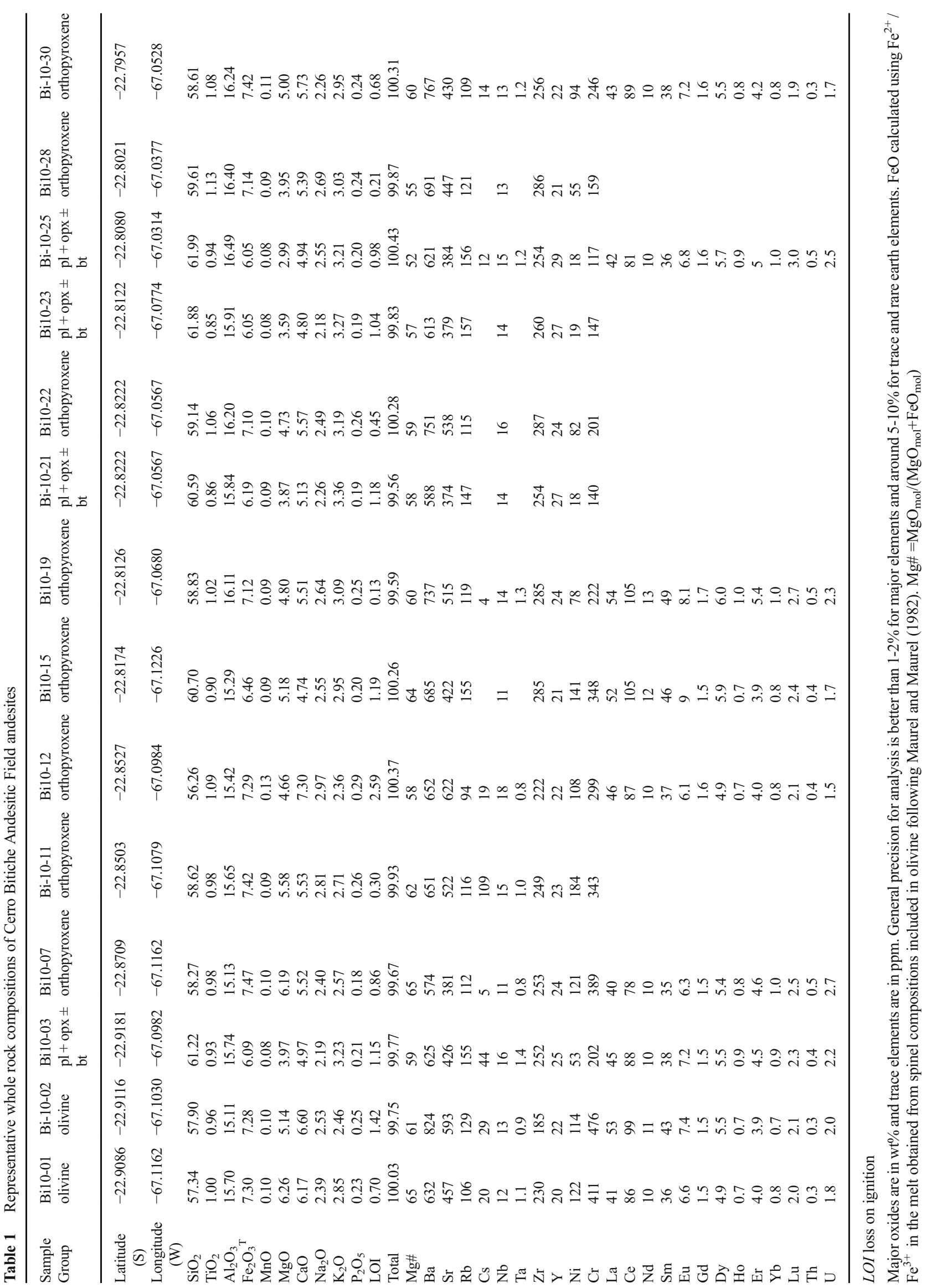

